\title{
Um estudo psicossocial dos significados e sentidos expressos nas músicas de MV Bill
}

\author{
Jaison Hinkel \\ Universidade Federal de Santa Catarina \\ Lorena de Fátima Prim \\ Fundação Universidade Regional de Blumenau
}

\begin{abstract}
Resumo
Este artigo tem por propósito estudar os significados e sentidos expressos nas letras das músicas de MV Bill, um dos ícones do rap nacional, com o intuito de possibilitar a compreensão da sua tendência afetivo-volitiva. Com base na Psicologia Sócio-Histórica, a pesquisa se caracteriza como um estudo de caso e utiliza como método a análise de conteúdo de quatro músicas: "Soldado do Morro", "Só Deus pode me julgar", "EMIVI" e "Atitude Errada". Os significados e sentidos das canções estudadas denunciam as dimensões objetiva, ética e subjetiva da dialética exclusão/inclusão social, bem como a proposta de enfrentamento desta condição. Assim, podem-se considerar tais músicas como indicadores de uma práxis ético-política que propõe ações coletivas com o objetivo de superar a situação de padecimento humano e utiliza a arte como expressão afetiva de potência de vida e criação, em prol da cidadania.
\end{abstract}

Palavras-chave: rap; significados; sentidos; psicologia sócio-histórica.

\begin{abstract}
A psychosocial study of the meanings expressed in the songs of $M V$ Bill. The purpose of this article is the analysis of meanings expressed in the song of MV Bill, one of the icons of the Brazilian rap, aiming at the comprehension of its affectionate-volitive tendency. The investigation is characterized as a case study and applies content analysis to four songs: "Soldado do Morro", "Só Deus pode me julgar", "EMIVI", and "Atitude Errada". The meanings and senses of the songs studied identify three dimensions of the dialectics social exclusion/enclosure (objective, ethical and subjective), as well as the clashing of this condition. It seems reasonable to consider such songs as indicators of an ethical-political practice that proposes collective actions with the objective of overcoming the situation of human suffering and utilizes art as affectionate expression of power of life and creation, in behalf of the citizenship.
\end{abstract}

Keywords: rap; meanings; senses; partner-historical psychology.

$\mathrm{N}$ os últimos anos pode-se perceber o surgimento de inúmeros grupos juvenis que atuam com uma sociabilidade e um espetáculo que envolve músicas, danças, roupas e desenhos. Estes jovens chamam a atenção da sociedade para a necessidade de se refletir acerca de um mundo marcado pela exclusão, violência e pela miséria (Herschmann, 2000). Uma destas possibilidades de ação juvenil é o rap, que, em meio a multiplicidade de gêneros musicais existentes no Brasil, é tomado como objeto deste estudo.

Mas o que é o rap? Por que estudá-lo? Ao procurar identificar a origem do rap, muitos estudiosos elegem os Estados Unidos da América como os criadores deste gênero musical. Segundo Silva (1999), os rappers não são apenas grupos musicais no sentido estrito, mas parte de um movimento estético-político surgido no final dos anos 70, nos EUA, composto por jovens negros e pobres, moradores da periferia nova-iorquina. Entretanto, sem desconsiderar tais informações, outros autores afirmam que a origem do rap remete ao canto falado africano, adaptado à música jamaicana da década de 1950 e influenciado pela cultura negra dos guetos americanos no período pós-guerra (Magro, 2002). Assim, apesar das divergências quanto ao seu surgimento, há um ponto de concordância entre os pesquisadores desta temática, que é a necessidade de considerar o rap em relação ao grafite (arte plástica) e ao break (dança), elementos que juntos formam o movimento hip-hop.

O movimento hip-hop se configura como um movimento juvenil que possibilitou uma crítica social a respeito de questões vivenciadas no cotidiano das periferias, como a desigualdade sócio-econômica, a discriminação racial e a violência, tomando a arte como instrumento de engajamento político capaz de re-elaborar o cotidiano de jovens pobres e, em sua maioria, afro-descendentes. Sobre a história do rap e do movimento hiphop, é possível obter-se mais informações em Andrade (1999), Herschmann (2000), Magro (2002), entre outros. 
A partir das contribuições de Duarte (1999), os rappers são concebidos neste estudo como músicos populares da periferia, literatos no sentido exato da palavra, pois buscam forjar uma literatura para si, não fazendo uma distinção entre produtor e consumidor, pelo contrário, procurando o debate e a discussão entre ambos. Silva (1999) contribui com esta pesquisa ao mencionar que as letras de rap são permeadas por expressões locais e exprimem o universo da periferia sempre a partir de uma perspectiva pessoal, de forma tal que toma a condição de exclusão como objeto de denúncia e reflexão. Assim, a escolha do rap como foco de estudo se dá a partir de seu reconhecimento enquanto uma possibilidade de re-elaboração da experiência juvenil urbana, um possível instrumento político (Andrade, 1999), um manifesto que pode penetrar no cotidiano dos excluídos para descrever com poesia aquilo que é aparentemente desprovido dela (Jovino, 1999).

O objetivo deste artigo é estudar os significados e sentidos expressos nas letras das músicas de MV Bill, a fim de possibilitar a compreensão da sua tendência afetivo-volitiva. Para tanto, é tomado como base para a realização da pesquisa a perspectiva da Psicologia Sócio-Histórica e as proposições epistemológicas da pesquisa qualitativa de Rey (2002), considerando que "a epistemologia qualitativa é um esforço na busca de formas diferentes de produção de conhecimento em psicologia que permitam a criação teórica acerca da realidade plurideterminada, diferenciada, irregular e histórica, que representa a subjetividade humana" (p. 29).

Esta perspectiva de investigação demarca uma opção epistemológica, teórica e política com uma forma de produção de conhecimento em Psicologia que não visa somente à coleta de dados, mas a construção de informações, pois a validade de um conhecimento não se verifica nos dados empíricos, mas na capacidade de diálogo que estes abrem ao pesquisador. Esta forma de produzir conhecimento acena para a complexidade presente no processo de análise das informações, uma vez que "o significado da informação não surge como produto de uma seqüência de dados, mas como resultado de sua integração no processo de pensamento que acompanha a pesquisa, que é, essencialmente, um processo de produção teórica" (Rey, 2002; p. 77). Neste prisma, o pesquisador não deve ter por objetivos a predição, a pura descrição ou o controle, mas a investigação do fenômeno com o intuito de conhecer, esclarecer, entender e interpretar os processos que o constituem. Isto configura o que o autor caracteriza como a transição de uma epistemologia da resposta para uma epistemologia da construção, perspectiva que busca reconhecer o lugar essencial que a singularidade ocupa na produção de conhecimento e ressaltar a condição social e histórica do ser humano.

Segundo Vygotski (1982/1992), há uma relação de constituição dialética entre pensamento e afetividade, sendo que por meio da análise dos motivos e interesses, desejos e necessidades, afetos e emoções, é possível compreender a tendência afetivo-volitiva do pensamento e da ação humana. Assim, para o autor russo, o sentido da palavra muda com o motivo, de forma que a compreensão de seu sentido consiste em penetrar nos motivos do interlocutor, uma vez que não basta apenas identificar as palavras expressas por um sujeito, é preciso compreender sua tendência afetivo-volitiva, já que o sentido da palavra é (re)construído conforme cada contexto no qual o sujeito está inserido. Nesta perspectiva, os significados são considerados o ponto de partida da análise, pois "sabe-se que eles contêm mais do que aparentam e que, por meio de um trabalho de análise e interpretação, pode-se caminhar para as zonas mais instáveis, fluidas e profundas, ou seja, para as zonas de sentido" (Aguiar, 2006, p. 14).

\section{Método}

Este artigo apresenta uma pesquisa exploratória, caracterizada como um estudo de caso que realiza a análise de conteúdo das letras de quatro músicas de MV Bill. Optou-se por trabalhar com as músicas, pois "o hip hop, embora englobe os elementos artísticos break, dança, e o grafite, pintura, é o rap, música, o instrumento de maior poder e valorização no movimento" (Andrade, 1999, p. 86).

A investigação se configurou mediante a análise de documentos de domínio público - as músicas. Conforme Spink (1999, p. 136), “os documentos de domínio público são produtos sociais tornados públicos. Eticamente estão abertos para análise por pertencerem ao espaço público, por terem sido tornados públicos de uma forma que permite a responsabilização”. Além das músicas, foram utilizadas fontes secundárias, como revistas, reportagens e entrevistas referentes ao rap e ao hip-hop, com o intuito de apreender a complexidade constituinte destes.

Jovem, com 32 anos, Bill é morador da periferia do Rio de Janeiro, nascido e criado na Cidade de Deus. Possui como produção artística três CDs, intitulados: Traficando Informação (1999), Declaração de Guerra (2002) e O bagulho é doido (2006). A escolha de MV Bill foi motivada em virtude de sua reconhecida contribuição para o rap brasileiro, considerando que ele é um dos ícones do movimento hip-hop nacional, o que pode ser evidenciado não apenas pela produção musical, mas também por sua publicação literária. Bill realizou uma pesquisa sobre o tráfico de drogas em diversas regiões do Brasil, trabalho que já proporcionou a publicação de três livros: Cabeça de Porco (Soares, Bill, \& Athayde, 2005), Falcão: meninos do tráfico (Bill \& Athayde, 2006) e Falcão: mulheres e o tráfico (Athayde \& Bill, 2007). Há de se ressaltar, no entanto, que a pesquisa que deu origem a este artigo foi realizada antes das publicações do rapper.

Após tomar contato com toda a obra musical do rapper, foram eleitas quatro letras para análise: "Soldado do Morro", "Só Deus pode me julgar", "EMIVI", e "Atitude errada". A seleção destas canções ocorreu considerando a capacidade das mesmas de sintetizar a riqueza e a complexidade dos significados e sentidos expressos no conjunto da obra musical do rapper. Vale salientar que o CD O bagulho é doido não foi utilizado nesta pesquisa, pois seu lançamento ocorreu após o término da mesma.

\section{Análise das letras das canções}

\author{
Soldado do Morro
}


A primeira canção a ser considerada se chama "Soldado do Morro", na qual se tem o relato da história de um jovem morador de periferia que, por considerar não ter alternativa, se torna um integrante do tráfico de drogas, numa tentativa de escapar da condição subalterna que ocupa diante da sociedade:

Minha condição é sinistra / Não posso dar rolé, não posso ficar de bobeira na pista / Na vida que eu levo eu não posso brincar / Eu carrego uma nove e uma HK/ pra minha segurança e tranqüilidade do morro / Se pá, se pam, eu sou mais um soldado morto / Vinte e quatro horas de tensão / Ligado na polícia, bolado com os alemão.

Aqui, pode-se visualizar o retrato do sofrimento éticopolítico que advém da condição de medo, insegurança (violência associada à morte) e tensão constante que impera na vida dos jovens participantes do tráfico de drogas, de forma tal que a segurança tanto do morro, quanto do próprio "soldado", é garantida por ele próprio e pelas suas armas, sendo a morte uma conseqüência para quem fica de "bobeira na pista". Falar em sofrimento ético-político é considerar a afetividade na análise da dialética exclusão/inclusão, de modo que "o sofrimento ético-político retrata a vivência cotidiana das questões sociais dominantes em cada época histórica, especialmente a dor que surge da situação social de ser tratado como inferior, subalterno, sem valor, apêndice inútil da sociedade" (Sawaia, 2001b, p. 104). Destarte, o sofrimento ético-político é fruto da negação da humanidade, das necessidades básicas do ser humano, de sua potência de liberdade e felicidade (Sawaia, 2003a).

Conforme Cintra (2002), há duas qualidades de medo, o medo bom e o ruim. Ao pesquisar a significação do glaucoma para seus portadores, a autora indica que há duas qualidades de medo, o medo bom e o ruim. O primeiro é aquele que potencializa o sujeito para a ação, fazendo com que procure agir sobre suas afecções. Já o segundo, o medo ruim, aparece associado a um padecimento que imobiliza as ações do sujeito, fazendo com que tenha medo frente suas possibilidades de existência. "A diferença que existe entre ambos revela a tensão entre a potência de ação e de padecimento" (Cintra, 2002, p. 145). A partir desta perspectiva, pode-se compreender o medo na vida do jovem "soldado do morro" como um medo, ao mesmo tempo, bom e ruim. Pode ser considerado bom porque o medo da "condição sinistra" é o que impulsiona o sujeito a não ficar de "bobeira na pista" e a preservar sua vida. Ruim, pois MV Bill denuncia nesta música a condição de impotência e des-valor experimentada pela personagem desta narrativa, que, por não encontrar outra perspectiva de vida, acaba se envolvendo com o tráfico de drogas. Assim, ao mesmo tempo em que há a conotação de que a vida de um "soldado do morro" é angustiante e perigosa, tem-se também a afirmação de outro aspecto, que inclusive pode justificar a opção por esta "condição sinistra" - a idéia de que a personagem da canção, pertencente ao tráfico de drogas, adquire status social.

Várias vezes me senti menos homem / Desempregado e meu moleque com fome / É muito fácil vir aqui me criticar / A sociedade me criou, agora manda me matar / Me condenar e morrer na prisão / Virar notícia de televisão / Seria diferente se eu fosse mauricinho, criado a sustagem e leite ninho / Colégio particular, depois faculdade / Não, não é essa minha realidade / Sou caboquinho comum, com sangue no olho, com ódio na veia, soldado do morro [...] Fora da lei, chamado de elemento / Agora o crime que dá o meu sustento / Já pedi esmola, já me humilhei / Fui pisoteado, só eu sei o que eu passei / Eu Tô ligado, não vai justificar / Meu tempo é pequeno não sei o quanto vai durar / É pior do que pedir favor / Arruma um emprego, eu tenho filho pequeno seu doutor / Fila grande, eu e mais trezentos / Depois de muito tempo, sem vaga no momento / A mesma história todo dia é foda / É isso tudo que gera revolta.

O sofrimento ético-político, mediante o sentimento de inferioridade, é uma tônica nesta letra que retrata a vivência constante da humilhação e da vergonha por estar "desempregado" e ter o "moleque com fome", sem possibilidades de adquirir os bens de consumo propostos pela sociedade e sentindo-se "menos homem" diante de tal situação. Aqui, constata-se a vergonha inserida no bojo da construção da identidade social subalterna, surgida mediante as condições de inferioridade que são sentidas por um eu de menor valor que se encontra entre a situação de pobreza e o olhar do outro que lhe aparece como superior ou dominante. "A vergonha é um sentimento moral que nos inibe, limita a nossa ação, nosso expandir, encolhe nosso corpo e pode nos reduzir ao silêncio, nos excluir. Deixa-nos pequenos, infantis" (Vitalle, 2002, p. 118). Neste prisma, o "soldado do morro" é um jovem submetido e escravizado pelo olhar desqualificante do outro que imputa nele os sentimentos de vergonha e humilhação. A humilhação, por sua vez, "é o sentimento de ser ofendido. Menosprezado, rebaixado, inferiorizado, submetido, vexado e ultrajado pelo outro. É sentir-se um ninguém, sem valor, inútil; magoado, revoltado, perturbado, mortificado, indignado, com raiva" (Barreto, 2003, p. 188). A humilhação é um sentimento de imensa intensidade que está entrelaçado com múltiplas emoções, cujo núcleo é o medo e a vergonha, que submetem e escravizam o homem. É um sofrimento imposto pela negação do outro, legitimado no autoritarismo e no adoecimento, decorrente do fato de tratar o outro sujeito como um simples objeto.

A desigualdade social se faz retratada nesta canção, que denuncia e desmistifica a culpabilização do indivíduo pelo "seu fracasso" enquanto um consumidor em potencial da sociedade capitalista. Deste modo, quem não tem condições socioeconômicas para desfrutar do banquete desta sociedade é explorado, é "condenado", jogado para "morrer na prisão" e "virar notícia de televisão". A situação de desigualdade social estigmatiza o sujeito como "caboquinho comum com sangue no olho e ódio na veia", ou como "fora da lei, chamado de elemento", de maneira que o próprio sujeito passa a se reconhecer deste modo. Ou seja, a maneira como a sociedade está organizada promove as condições subjetivas e objetivas para que a personagem da canção se torne um "soldado do morro". MV Bill adverte que isto acontece justamente porque o "soldado do morro" é negro e pobre, morador da periferia, pois "seria diferente se fosse mauricinho, criado a sustagem e leite ninho".

Esta poesia ritmada denuncia a inclusão social perversa como uma necessidade que a sociedade tem de excluir incluindo 
para manter a ordem social (desigual, injusta e anti-ética). Noutras palavras, "todos estamos inseridos de algum modo, nem sempre decente e digno, no circuito reprodutivo das atividades econômicas, sendo a grande maioria da humanidade inserida através da insuficiência e das privações, que se desdobram para fora do econômico" (Sawaia, 2001a, p. 08).

Eu tô ligado qual é, sei qual é o final / Um saldo negativo, menos um marginal / Pra sociedade contar um a menos na lista e engordar a triste estatística/ De jovens como eu que desconhecem o medo / Seduzidos pelo crime desde muito cedo / Mesmo sabendo que não há futuro / Eu não queria tá nesse bagulho [...] Não sei se é pior virar bandido / Ou se matar por um salário mínimo.

Neste trecho, fica visível que o jovem, ao ingressar no tráfico de drogas, tem consciência que continuará na posição dialética excluído/incluído perversamente, independente da quantidade de dinheiro, poder ou fama que possa angariar para si. Isto porque ele sabe que sua ação como "soldado do morro" acaba por cair na situação de desqualificação social, pois sua "condição sinistra" legitima a posição de subalterno, de "marginal", apesar de estar tentando construir para si aquilo que a sociedade não lhe autorizou: um projeto de vida. Deste modo, o tráfico de drogas é visto, contraditoriamente, como uma saída para a condição de humilhação, vergonha e medo, na medida em que permite acesso ao dinheiro, poder e fama, ao mesmo tempo em que legitima para o sujeito a idéia de que seu projeto de vida é inviável.

MV Bill finaliza a música ao mostrar que o jovem "soldado do morro" sabe que sua hora de morrer pode estar próxima e que ele será "menos um marginal/ Pra sociedade contar um a menos na lista e engordar a triste estatística". Isto é, "mesmo sabendo que não há futuro" para sua condição de "soldado do morro", ele continua a arriscar sua vida até que a morte lhe seja fatídica, pois não sabe se "é pior virar bandido ou se matar por um salário mínimo". Assim, "não lhes interessa qualquer sobrevivência, mas uma específica, com reconhecimento e dignidade" (Sawaia, 2001b, p. 115). É exatamente a necessidade de ser reconhecido como gente que move a personagem da canção a se tornar um "soldado do morro", tendo em vista que este foi o caminho visualizado por ele para ser reconhecido perante a sociedade. O "soldado do morro" surge, então, como uma tentativa de recuperar, nem que seja por meio da marginalidade, o reconhecimento social que sua condição estigmatizada lhe impossibilita.

\section{Só Deus pode me julgar}

A segunda letra estudada é a da canção "Só Deus pode me julgar":

Mais de 500 anos de angústia e sofrimentos / Me acorrentaram, mas não meus pensamentos [...] Entramos pela porta de serviço, nossa grana não / Tá bom só pra quem manda bater / Pisando nos humildes e fazendo nosso ódio crescer / CV, MST, CUT, UNE, CUFA, PCC / O mundo se organiza, cada um a sua maneira / Continuam ironizando, vendo como brincadeira / Besteira, coisa de moleque revoltado / Ninguém mais quer ser boneco / Ninguém quer ser controlado, vigiado, programado, calado, ameaçado / Se for filho de bacana, o caso é abafado / A gente é que é caçado, tratados como réu / As armas que eu uso é microfone, caneta e papel / A socialite assiste a tudo calada / Salve! Salve! Salve! Oh pátria amada, mãe gentil / Poderosos do Brasil, que distribuem para as crianças, cocaína e fuzil.

Neste trecho, MV Bill afirma que os "pensamentos" não podem ser "acorrentados", mesmo apesar de toda "angústia" e "sofrimento", concepção esta que é evidenciada mais claramente quando ele fala que "tá bom só pra quem manda bater" e que o "mundo se organiza cada um a sua maneira". Nestas palavras, é demarcada a necessidade de resistir às pressões sociais e criar novas formas de relação social para diminuir o sofrimento éticopolítico. Com isto, MV Bill aponta que é preciso novas formas de intersubejtividade, onde "ninguém mais quer ser boneco, ninguém quer ser controlado, vigiado, programado, calado e ameaçado", pois é preciso romper com a conivência em relação à desigualdade e à injustiça e desmascarar a situação de que "se for filho de bacana o caso é abafado (...); a socialite assiste a tudo calada e os poderosos do Brasil, que distribuem para as crianças, cocaína e fuzil".

O estabelecimento de relações com vistas a desconstrução da organização social desigual necessita que o sujeito potencialize suas ações para partir em busca da emancipação. Segundo Sawaia (2001b), inspirada em Espinosa, potencializar "significa atuar, ao mesmo tempo, na configuração da ação, significado e emoção, coletivas e individuais. Ele realça o papel positivo das emoções na educação e na conscientização, que deixa de ser fonte de desordem e passa a ser vista como fator constitutivo do pensar e agir racionais" (p. 113).

Para a autora, o conceito de potência de ação é utilizado no combate da servidão, que leva o homem viver ao acaso dos encontros, como joguete dos acontecimentos e colocar somente nos outros o sentido da própria existência.

Como pode ser tragédia a morte de um artista e a morte de milhões apenas uma estatística? / Fato realista, de dentro do Brasil / Você que chorava lá no gueto, ninguém te viu / Sem fantasiar / Realidade dói / Segregação, menosprezo é o que destrói / A maioria é esquecida no barraco / Que ainda é algemado, extorquido e assassinado / Não é moda, quem pensa incomoda / Não morre pela droga, não vira massa de manobra / Não me idolatra mauricinho da TV / Não deixa se envolver, porque tem proceder / Pra que? Por que? / Só tem paquita lôra/ Aqui não tem preta como apresentadora / Novela de escravo a emissora gosta / Mostra os pretos chibatados pelas costas / Faz confusão na cabeça de um moleque que não gosta de escola e admira uma intra-tek / Clik - clek, mão na cabeça! Quando for roubar dinheiro público, vê se não esqueça que na sua conta tem a honra de um homem envergonhado ao ter que ver sua família passando fome / Ordem, progresso e perdão / Na terra onde quem rouba muito não tem punição.

Aqui se pode perceber a denúncia das dimensões da dialética exclusão/inclusão social perversa contidas nas reflexões de Sawaia (2001a). A desigualdade social e a dimensão ética da injustiça são denunciadas no momento em que MV Bill fala que "a maioria é esquecida no barraco, que ainda é algemado, 
extorquido e assassinado" e no fato de que a morte de um artista é uma "tragédia", enquanto a morte de milhares de brasileiros pobres é "apenas uma estatística". Isto é reafirmado quando menciona que não há apresentadoras negras de programas de televisão, que "novela de escravo a emissora gosta" e que o Brasil "é a terra onde quem rouba muito não tem punição".

A dimensão subjetiva da condição de exclusão/inclusão perversa é expressa na dura realidade da "segregação" e do "menosprezo" que "destrói" e da "vergonha ao ter que ver a família passando fome", experiências advindas da desigualdade e da injustiça social, que apesar de serem geradas na intersubjetividade, são personificadas e sentidas como sofrimento ético-político por um eu de menor valor. "Essa política da afetividade gera e reforça o sofrimento ético-político: quem sofre passa a sentir-se ainda mais culpado por não conseguir reagir, por não se bastar" (Sawaia, 2003a, p. 60).

\section{EMIVI}

A próxima música considerada foi a chamada "EMIVI". EMIVI é um jogo de palavras que o rapper faz para se referir as siglas iniciais de seu dístico MV, que significa mensageiro da verdade. Nela pode-se perceber que além da denúncia das diversas facetas da dialética exclusão/inclusão social perversa, MV Bill expressa sua concepção de que é preciso "resistir" e propor ações que possam modificar as relações na intersubjetividade e a dinâmica de organização social, de modo que a felicidade de poucos não seja alcançada mediante o sofrimento da grande maioria da população brasileira.

O Pesadelo da elite tá de volta, não morri / No caminho verminoso só Deus sabe o que eu senti / Falo do que eu sei / Digo o que eu li / Mantendo a coerência, não exponho o que eu não vi / Quando a chapa esquentou, você notou que eu não corri / Anunciaram seu veneno na tv mas não bebi / Diferente do preto que não quer se assumir / A esse tipo de lavagem cerebral sobrevivi / No meio de uma guerra foi onde eu nasci / No berço da exclusão foi onde eu cresci / Não me intimidei, foi preciso resistir / Faço parte do Quilombo comandado por Zumbi / De lá pra cá ou daqui pra li / Enquanto você chora quem controla o poder sorri / Vou guerrear pra não deixar me destruir / É por essas e por outras que eu sou EMIVI.

A temática desta canção gira em torno da necessidade de resistir às pressões exteriores, de tal maneira que o sujeito possa se posicionar no mundo perante as condições que a sociedade lhe oferece. Justamente por não beber o "veneno da TV", MV Bill se considera o pesadelo da elite e justifica porque ele é o EMIVI. Pode-se compreender que esta auto-denominação como o mensageiro da verdade, demarca que Bill se identifica como um porta-voz da periferia, relator da situações que ele e seus semelhantes vivenciam cotidianamente.

Nesta letra, o rapper afirma ter nascido no meio de uma guerra e ter crescido no "berço da exclusão", condições estas que lhe possibilitaram trilhar um "caminho verminoso", de forma que "só Deus sabe" o que ele sentiu. Mesmo em meio a estas dificuldades, MV Bill ratifica a idéia de que é preciso "resistir" e procurar "guerrear" para não deixar se "destruir", o que entra em consonância com as proposições de Sawaia (2003b), a respeito do conceito de potência de ação como a força de combate ao sofrimento e de conservação e expansão da vida. Nota-se ainda que o cantor afirma fazer parte do "Quilombo de Zumbi", uma referência acerca da necessidade do sujeito pertencer a um grupo, considerando que "o objetivo de cada um é rentabilizar maximamente sua potência, diz Espinosa, ao mesmo tempo que afirma, que só o conseguimos, quando nos unimos a outros, alargando nosso campo de ação" (Sawaia, 2001b, p. 116).

Frustrações no passado eu senti / Investigações no presente eu sofri / E descobri que na pista é cada um por si / É preciso ter contexto para não cair / O meu orgulho, o meu respeito eu não achei por aí / Pra deixar filhinho de papai me inibir, nem rir quando for avaliar o meu Q.I / Vai ver que tenho um veneno pra jogar e ele engolir.

"Frustrações" e "investigações" também são aspectos vivenciados pelos moradores das favelas do Brasil, o que sinaliza novamente o sofrimento e a discriminação experimentados cotidianamente por estes seres humanos. Entretanto, MV Bill afirma que "na pista é cada um por si”, isto é, na organização social neoliberal, individualista, "é preciso ter contexto para não cair", de modo que o "orgulho" e o "respeito" não podem ser ignorados e violados quando um "filhinho de papai vier avaliar o Q.I.”. Neste sentido, o rapper aponta a noção de que é imprescindível manter uma posição que não permite que o outro se coloque como modelo/padrão a ser seguido, ou seja, é necessário impedir que o discurso seja feito de "fora para dentro", de modo que alguém dita para o sujeito o que e como ele deve ser. Ao invés disto, o cantor fala da necessidade de se criar um discurso de "dentro para dentro", de forma que o sujeito se posicione no mundo conforme sua singularidade e não segundo um modelo importado de comportamento. Aqui é importante refletir a respeito da constante necessidade de "resistir/guerrear/sobreviver" que MV Bill menciona em suas letras e o conceito de participação social. De acordo com Sawaia (2002, p. 126), "participamos quando, em nós ou fora de nós, algo se faz do qual somos causa adequada, que podemos conhecer clara e distintamente. Quando isso não acontece, submetemonos à participação". Na perspectiva desta autora, participar trata da passagem da passividade à atividade, da heteronomia à autonomia e não se restringe a um processo exclusivamente racional, visto que abarca não somente a tomada de consciência, mas o sujeito como um todo, vivida como necessidade e desejo do eu. Destarte, "a alegria, a felicidade e a libertação são necessidades tão fundamentais quanto aquelas, classicamente, conhecidas como básicas: alimentação, abrigo e reprodução" (Sawaia, 2003a, p. 55).

\section{Atitude Errada}

A última música estudada é "Atitude Errada". Nesta letra se pode constatar que além de fazer a denúncia dos fenômenos que promovem o sofrimento ético-político, MV Bill indica um possível caminho para o enfrentamento desta condição.

MV Bill está de volta tentando conscientizar vocês / Parando para pensar, botando a cabeça no lugar / Pedindo a Deus pra nos ajudar [...] Tapa na cara, soco no olho, tiro no peito, sangue no chão / Tem que ser trocado por um simples aperto de mão / 
Entre irmãos informação, necessidade / Apesar de ser uma letra pode se tornar verdade / Depende dela, depende dele, depende de mim, depende de você / A vida é curta, procure alguma coisa boa para fazer / Parar de se matar, nosso inimigo é outro / Prejudicado nessa guerra apenas nosso povo [...] Enquanto eu falo a verdade você só pensa em beber / Só pensa em mulher, sem camisinha, assim tu vai morrer / É preciso união, é preciso informação, para acabar, para acabar com a nossa destruição / Parar de brigar, parar de beber demais, porque desse jeito vai ser difícil encontrar a paz.

Três palavras são peças-chave para que se possa compreender as músicas de MV Bill: conscientização, informação e união, pois é a partir deste ponto que o rapper indica a necessidade de uma mudança nas esferas política - para que a informação veicule igualitariamente e haja uma maior distribuição de renda - e subjetiva, de maneira que a tomada de consciência e a união possam transformar as atitudes de cada sujeito. $\mathrm{O}$ cantor menciona que a violência, a drogadição, o relacionamento promíscuo, a falta de informação e a desunião são aspectos que favorecem a manutenção das condições sociais promovedoras de sofrimento ético-político e que, portanto, são "atitudes erradas". Nesta perspectiva, é necessário se conscientizar de que é "preciso união, é preciso informação, porque desse jeito vai ser difícil encontrar a paz".

A conscientização, na perspectiva de MV Bill, não fica restrita ao puro ato cognitivo, pois em todas as músicas estudadas é constante a presença dos aspectos afetivos existentes na vida dos moradores de periferia, seja nos momentos em que o rapper utiliza-os para retratar o sofrimento ético-político, seja quando demarca a necessidade de mudanças neste tipo de relação de inclusão social perversa. Tanto para denunciar, quanto para propor formas de ação para superar esta condição de padecimento humano, o rapper utiliza um discurso permeado pela afetividade, o que demarca sua fala a partir de um lugar que é comum a todos os moradores de periferia: o de ser humano. Nestes termos, conscientização remete a necessidade de refletir sobre as relações que cada sujeito estabelece com os outros que lhe afetam, o que por sua vez, possibilita um re-posicionamento perante as demandas sociais. Conscientização não como um fenômeno abstrato, mas como uma ação implicada afetivamente, com intencionalidade prática de transformação social, como sinônimo de re-significação das possibilidades de mudanças objetivas/ subjetivas na vida de cada sujeito singular/coletivo em busca da diminuição do sofrimento e do aumento da potência de ação.

Os significados e sentidos das composições de MV Bill apresentam a característica fundamental do processo de participação social proposto por Sawaia (2002), no qual participar é estar implicado afetivamente. Carregadas de afetividade, estas músicas descrevem as vivências objetivas advindas de uma ordem social baseada na inclusão perversa e relatam o sentimento de vergonha, culpa, humilhação, tristeza, ódio e medo. Tais sentimentos inibem e limitam a ação e se apresentam como essenciais para a constituição de uma identidade social subalterna. Entretanto, outra parte das canções propõe o enfrentamento desta condição e expressa a importância da união/parceria, lealdade, humildade, liberdade, esperança, fé e solidariedade. Desta maneira, a afetividade é expressa nas músicas consideradas neste artigo como uma importante dimensão da ação política no movimento hip-hop. Elas representam tanto a denúncia do sofrimento ético-político, como a possibilidade de potencialização para a busca da transformação psicossocial da condição subjetiva e material na qual vivem seus protagonistas (Hinkel \& Prim, 2005).

Esta busca pela transformação social é uma característica que indica para o caráter de movimento social existente no hiphop. Conforme Scherer-Warren (1996), um movimento social configura-se por ser uma ação coletiva para a transformação da vida social (a práxis), voltada para a realização de objetivos comuns, para além de interesses particulares (o projeto), seguindo a princípios valorativos comuns (a ideologia) e com uma organização diretiva mais ou menos definida (a organização e sua direção). A partir destes indicadores, pode-se considerar que o movimento hip-hop age com o intuito de criticar e superar a forma como são utilizados os recursos e os valores sociais dominantes, seja na ordem do conhecimento, da economia ou da ética, em busca da transformação da realidade vivida na periferia, o que permite considerá-lo um movimento social organizado, com base na expressão artística, política e educativa, em prol da cidadania. A discussão sobre a configuração (ou não) do hiphop como movimento social extrapola os limites deste artigo, entretanto há de se assinalar que, para que se possa compreender esta questão, é preciso atentar para além das letras de rap e considerar as ações desenvolvidas pelas posses. Segundo Silva (1999), as posses são uma espécie de família forjada, um espaço próprio pelo qual jovens não apenas produzem arte, mas apoiamse mutuamente, desenvolvendo estratégias que possibilitam uma re-interpretação da experiência juvenil periférica.

Cidadania é aqui entendida para além da igualdade de direitos, enquanto fenômeno político, histórico, social e também inter e intra-subjetivo (Sawaia, 1994). Neste prisma, ao falar de cidadania é preciso ter como alicerce fundamental a alteridade, tomar como norte a idéia de humanidade e em seu centro a temática da subjetividade/singularidade, o que permite ir na contracorrente do individualismo, da massificação e da homogeneização. Assim, para a autora "cidadania é consciência dos direitos iguais, mas esta consciência não se compõe apenas do conhecimento da legislação e do acesso à justiça. Ela exige o sentir-se igual aos outros, com os mesmos direitos iguais" (Sawaia, 1994, p. 152).

\section{Considerações finais}

A importância de se estudar a música como uma questão social aponta para a necessidade de se reconhecer que "os músicos transmitem uma mensagem nas suas letras e um sentido na sua música, podendo trazer elementos novos para a reflexão sobre os valores sociais, mesmo quando tentam mostrar somente as coisas tais como estão acontecendo agora" (Maheirie, 2002, p. 49). Deste modo, as canções estudadas neste artigo podem ser consideradas como construções dialéticas que expressam a "realidade" da população da periferia que vive o dia-a-dia da dialética exclusão/inclusão social perversa. Seja na canção "Soldado do Morro", na qual MV Bill relata a vida de um 
jovem integrante do tráfico de drogas, seja na música "Só Deus pode me julgar", que versa, principalmente, sobre o sofrimento ético-político vivido pelos moradores de periferia, seja na letra de "EMIVI" ou de "Atitude Errada", nas quais se objetiva a conscientização para o enfrentamento do sofrimento éticopolítico e para a necessidade de se propor ações coletivas que o transcendam, pode-se considerar que a tendência afetivo-volitiva destas músicas está vinculada à busca de cidadania.

A partir da perspectiva sócio-histórica, pode-se conceber tais músicas como indicadores de uma práxis ético-política (Sawaia, 2003b), apresentando propostas de ação em relação a afetividade enquanto dimensão política de luta pela superação do sofrimento. Neste sentido, considera-se as músicas estudadas neste artigo como mediação para a potencialização dos jovens de periferia no combate às causas de seu sofrimento, ressaltando que a práxis ético-política tem como meta "libertar os sujeitos do peso da superstição e do preconceito, fazendo-os compreender e aceitar as causas das paixões, e convidando-os ao exercício de sua própria capacidade para pensar e agir" (Sawaia, 1998, p. 131).

Apesar da análise destas músicas indicar que o rap pode se propor como opção à marginalidade, expressão afetiva de potência de vida e criação, mediação em busca da cidadania, não é possível determinar como o ouvinte irá se apropriar destas músicas. Isto porque ao contemplar uma música o ouvinte se apropria dos significados expressos nesta e produz a partir dela novas zonas de sentido que não necessariamente convergem com a perspectiva de seu compositor. Desta maneira, "a obra de arte em si não é boa nem má, ou, para ser mais exato, implica enormes possibilidades de bem e de mal, dependendo tudo isto apenas do emprego e do destino que dermos a este instrumento" (Vygotsky, 1970/1999, p. 322).

Por fim, longe de propor uma teorização homogênea e generalista sobre o rap nacional, este artigo apenas produziu uma zona de inteligibilidade sobre as músicas de MV Bill, indicando que o rap pode tomar o sentido de possibilitar a denúncia e o enfrentamento do sofrimento ético-político, bem como a construção de ações coletivas perante as condições desiguais, injustas e anti-éticas existentes na sociedade brasileira.

\section{Referências}

Aguiar, W. M. J. (2006). A pesquisa junto a professores: fundamentos teóricos e metodológicos. In W. M. J. Aguiar (Org.), Sentidos e significados do professor na perspectiva sócio-histórica: relatos de pesquisa (pp.11-22). São Paulo: Casa do Psicólogo.

Andrade, E. N. (1999). Hip-Hop: movimento negro juvenil. In E. N. Andrade (Org.), Rap e educação: rap é educação (pp. 83-91). São Paulo: Summus.

Athayde, C., \& Bill, M. V. (2007). Falcão: mulheres e o tráfico. Rio de Janeiro: Objetiva.

Barreto, M. (2003). Violência, saúde e trabalho: uma jornada de humilhações. São Paulo: Educ.

Bill, M. V.. (1999). Traficando informação [Cd]. Manaus: BMG. Digital, estéreo.

Bill, M. V.. (2002). Declaração de guerra [Cd]. Manaus: BMG. Digital, estéreo.

Bill, M. V. (2006). Falcão: o bagulho é doido [Cd]. Manaus: BMG. Digital, estéreo.
Bill, M. V., \& Athayde, C. (2006). Falcão: meninos do tráfico. Rio de Janeiro: Objetiva.

Cintra, F. A. (2002). O medo bom e o medo ruim: a dimensão emocional na resistência à exclusão pelo envelhecimento em portadores de glaucoma. In B. B. Sawaia \& M. R. Namura (Orgs.), Dialética exclusão/inclusão: reflexões metodológicas e relatos de pesquisas na perspectiva da psicologia social crítica (pp. 143-152). Taubaté: Cabral Editora Universitária.

Duarte, G. R. (1999). A arte na (da) periferia: sobre...vivências. In E. N. Andrade (Org.), Rap e educação: rap é educação (pp. 13-22). São Paulo: Summus.

Herschmann, M. (2000). O Funk e o Hip-Hop invadem a cena. Rio de Janeiro: Editora da Universidade Federal do Rio de Janeiro.

Hinkel, J., \& Prim, L. F. (2005). Arte como expressão afetiva no hip-hop [Resumo]. In ULAPSI (Org.), Anais do I Congresso Latino-Americano da Psicologia - ULAPSI. Cd-Rom. São Paulo: Autor.

Jovino, I. S. (1999). Rapensando os PCNs. In E. N. Andrade (Org.), Rap e educação: rap é Educação (pp. 161-168). São Paulo: Summus.

Magro, V. M. M. (2002). Adolescentes como autores de si próprios: cotidiano, educação e o hip-hop. Cadernos Cedes, 22(57), 63-75.

Maheirie, K. (2002). Música popular, estilo estático e identidade coletiva. Psicologia Política, 2(3), 39-54.

Rey, F. G. (2002). Pesquisa qualitativa: caminhos e desafios. São Paulo: Pioneira Thompson Learning.

Sawaia, B. B. (1994). Cidadania, diversidade e comunidade: uma reflexão psicossocial. In M. J. P. Spink (Org.), A cidadania em construção: uma reflexão transdisciplinar (pp. 147-156). São Paulo: Cortez.

Sawaia, B. B. (1998). A crítica ético-epistemológica da psicologia social pela questão do sujeito. Psicologia e Sociedade,10(2), 117-136.

Sawaia, B. B. (2001a). Introdução: exclusão ou inclusão social perversa? In B B. Sawaia (Org.), As artimanhas da exclusão: análise psicossocial e ética da desigualdade social (pp. 07-13). Petrópolis: Vozes.

Sawaia, B. B. (2001b). O sofrimento ético-político como categoria de análise da dialética exclusão/inclusão. In B. B. Sawaia (Org.), As artimanhas da exclusão: análise psicossocial e ética da desigualdade social (pp. 97-118). Petrópolis: Vozes.

Sawaia, B. B. (2002). Participação social e subjetividade. In A. Sposati, B. B Sawaia, D. Dallari \& I. Warren (Orgs.), Ambientalismo e participação na contemporaneidade (pp. 115-133). São Paulo: Educ.

Sawaia, B. B. (2003a). Fome de felicidade e liberdade. In Centro de Estudos e Pesquisas em Educação, Cultura e Ação Comunitária - CENPEC (Org.), Muitos lugares para aprender (pp. 53-63). São Paulo: CENPEC/ Fundação Itaú Social/ UNICEF.

Sawaia, B. B. (2003b). Família e afetividade: a configuração de uma práxis ético-política, perigos e oportunidades. In A. R. Acosta, \& M. A. F. Vitalle (Orgs.), Família: redes, laços e políticas públicas (pp. 39-50). São Paulo: IEE/PUCSP.

Scherer-Warren, I. (1996). Redes de Movimentos Sociais. São Paulo: Loyola.

Silva, J. C. G. (1999). Arte e educação: a experiência do movimento hip-hop paulistano. In E. N. Andrade (Org.), Rap e educação: rap é educação (pp. 23-38). São Paulo: Summus.

Soares, L. E., Bill, M. V., \& Athayde, C. (2005). Cabeça de Porco. Rio de Janeiro: Objetiva.

Spink, P. (1999). Análise de documentos de domínio público. In M. J. Spink (Org.), Práticas discursivas e produção de sentidos no cotidiano: aproximações teóricas e metodológicas (pp. 123-151). São Paulo: Cortez.

Vitalle, M. A. F. (2002). O obscuro sentimento da vergonha. In B. B Sawaia \& M. R. Namura(Orgs.), Dialética exclusão/inclusão: reflexões metodológicas e relatos de pesquisas na perspectiva da psicologia social crítica (pp. 115127). Taubaté: Cabral Editora Universitária.

Vygotski, L. S. (1992). Obras escogidas (Tomo 2). Madri: Visor. (Publicado originalmente em 1982)

Vygotsky, L. S. (1999). Psicologia da arte. São Paulo: Martins Fontes. (Publicado originalmente em 1970) 
Jaison Hinkel, mestre em Psicologia pela Universidade Federal de Santa Catarina (UFSC), é doutorando em Psicologia na mesma instituição e pesquisador do Núcleo de Pesquisas em Práticas Sociais, Relações Éticas, Estéticas e Processos de Criação. Endereço para correspondência: Rua Marcial do Nascimento, 228 (Bairro Bela Vista); Cidade Gaspar, Santa Catarina; CEP 89110-000. Fone: (47) 3397-2648. E-mail: jaisonhinkel@yahoo.com.br

Lorena de Fátima Prim, doutora em Psicologia Social pela Pontifícia Universidade Católica de São Paulo, é professora na Fundação Universidade Regional de Blumenau. E-mail: lprim@yahoo.com.br 